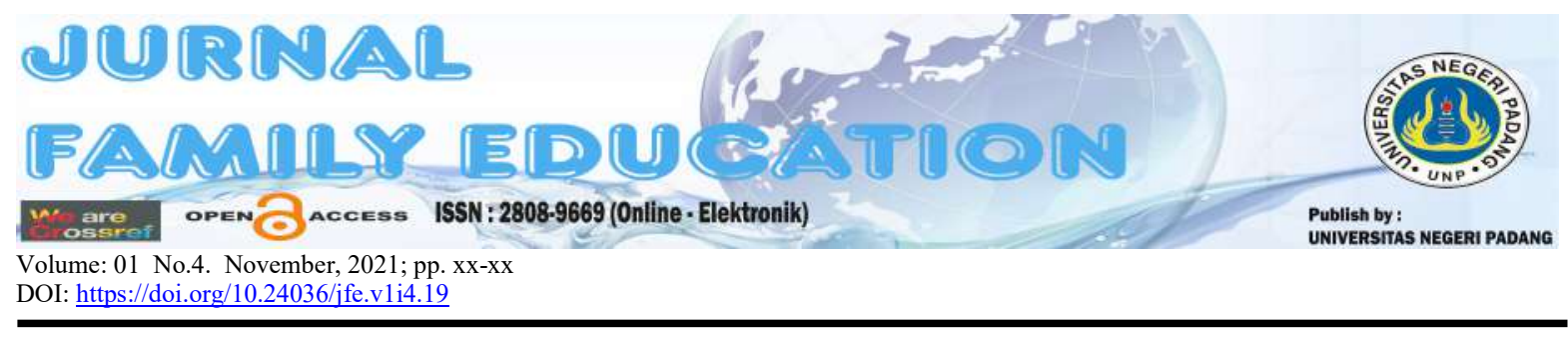

\title{
Analisis Faktor Penghambat dalam Perkembangan Kecerdasan Interpersonal Anak di Taman Kanak-kanak
}

\author{
Desi Karmila, Delfi Eliza \\ Universitas Negeri Padang \\ * e-mail: desikarmila32@gmail.com; deliza.zarni@gmail.com
}

\begin{abstract}
Interpersonal intelligence is very important for children to be easily accepted in the community because children with interpersonal intelligence have many skills, namely the ability to empathize (sharing, helping and helping others), the ability to recognize other people's thoughts, the ability to make friends, and establish social relationships so that they can build relationships. positive relationships with others. Some of the inhibiting factors for children's interpersonal intelligence include the child's individual home environment, parenting patterns that are too authoritarian and overprotective. Therefore, teachers and parents should pay attention to every development and interpersonal intelligence of children so that children have good interaction skills in their daily lives
\end{abstract}

Keywords: Inhibiting Factors; Interpersonal Intelligence CC) (1) \$ licensees may copy, distribute, display and perform the work and make derivative works and remixes based on it only if they give the author or derivative works and remixes based on it only for non-commercial purposes.

\section{PENDAHULUAN}

Anak usia dini merupakan individu yang sedang berada pada masa pertumbuhan dan perkembangan yang pesat. Anak usia dini adalah individu yang berada pada rentang usia 0 sampai 8 tahun. Anak usia dini sangat membutuhkan bantuan orang dewasa dalam proses tumbuh kembangnya. Oleh karena itu, peranan keluarga dan lingkungan sekolah sangat mempengaruhi perkembangan anak.

Pendidikan anak usia dini (PAUD) ditujukan bagi anak prasekolah agar anak dapat mengembangkan potensinya sejak usiia dini, yaitu dengan memberikan rangsangan pendidikan untuk membantu pertumbuhan dan perkembangan jasmani dan rohani anak. Menurut National Association for the Education of Young Children (NAEYC) rentang usia anak usia dini adalah 0-8 tahun. Menurut Undang-Undang Nomor 20 Tahun 2003 tentang Sistem Pendidikan Nasional berkaitan dengan Pendidikan Anak Usia Dini tertulis pada Pasal 28 Ayat 1 yang berbunyi "Pendidikan Anak Usia Dini diselenggarakan bagi anak sejak lahir sampai dengan enam tahun dan bukan merupakan prasyarat untuk mengikuti pendidikan dasar".

PAUD terdiri dari Taman Penitipan Anak (TPA), Kelompok Bermain (KB) dan Taman Kanak-kanak.Salah satu jalur pendidikan formal dalam pendidikan anak usia dini (PAUD) dikenal dengan istilah Taman Kanak-kanak (TK). Taman Kanak-kanak merupakan salah satu sarana pendidikan jalur formal bagi anak berusia 4 sampai 6 tahun. Pada usia dini pertumbuhan dan perkembangan anak terjadi sangat pesat sehingga pada saat ini menjadi waktu yang tepat untuk memberikan stimulasi dalam masa pembelajaran anak untuk mengembangkan seluruh aspek perkembangan dan kecerdasan anak. 
Setiap anak cendrung memiliki kecerdasan yang berbeda, ada yang memiliki kecerdasan yang tinggi di aspek tertentu sedangkan rendah di bidang lainnya. Hal tersebut dipengaruhi oleh bawaan dan stimulasi sejak usia dini. Stimulasi yang tepatakan menjadikan anak individu yang memiliki kualitas kecerdasan yang tinggi. Kecerdasan tersebut meliputi kecerdasan 1) Logika matematika; 2) Verbal linguistik; 3)Spasial; 4)Musikal; 5)Kinestetik; 6) Interpersonal; 7) Intrapersonal; 8)Naturalis dan; 9) Spiritual(Islami, 2016).Pembelajaran anak hendaknya mampu meningkatkan seluruh kecerdasan anak sehingga anak mampu menyesuaikan diri dalam lingkungan masyarakat secara baik. Salah satu kecerdasan yang penting ditingkatkan pada anak usia dini adalah kecerdasan Interpersonal.

Setiap anak dalam perkembangan tidak terlepas dari lingkungan sosialnya. Kemampuan berinteraksi atau berprilaku dengan orang lain di lingkungan sosial penting agar bisa diterima dengan baik di lingkungannya. Kecerdasan interpersonal berkaitan dengan kehidupan sosial.Manusia disebut makhluk sosial karena dalam kehidupannya akan selalu berinteraksi dengan manusia lainnya, begitu juga dengan anak.Anak membutuhkan bantuan orang lain juga, baik dari keluarganya atau teman sebayanya, namun walaupun anak usia dini masih banyak membutuhkan orang lain tetapi mereka masih banyak yang belum bisa menyesuaikan diri dan dapat menjalin hubungan dengan orang lain(Pahrul et al., 2019). Menurut (Kusumawati \& Yasin, 2020) pengertian kecerdasan interpersonal adalah kemampuan untuk berhubungan dengan orangorang disekitar, kecerdasan ini adalah kemampuan untuk memahami dan memperkirakan perasaan, temperamen, suasana hati, maksud dan keinginan orang lain dan menanggapinya secara layak. Anak yang memiliki kecerdasan interpersonal dapat dengan mudah menyesuaikan diri di lingkungannya.

Berdasarkan observasi dan wawancara peneliti di TK Pertiwi III Ladang Panjang ditemukan bahwa pengembangan kecerdasan interpersonal anak belum berkembang secara optimal. Hal tersebut terlihat dari masih ada beberapa anak yang menyendiri atau bermain sendiri dan tidak mau bergabung dengan teman-temannya. Oleh karena itu penulis ingin mengetahui apa saja factor penghambat dalam mengembangkan kecerdasan interpersonal anak yang diberi judul "Analisis Faktor Penghambat dalam Perkembangan Kecerdasan Interpersonal Anak di Taman Kanak-kanak Pertiwi III Ladang Panjang”

\section{METODE PENELITIAN}

Penelitian menggunakan metode deskriptif kualitatif. Penelitian dilakukan pada TK Pertiwi III Ladang Panjang. Teknik pengumpulan data melalui wawancara dan dokumentasi. Alat observasi yang digunakan berbentuk format wawancara dilakukan pada narasumber di lembaga-lembaga yang berkaitan dengan perlindungan anak. Data dokumentasi berupa foto, rekaman dan video sebagai lampiran untuk memperkuatkan hasil penelitian

\section{HASIL DAN PEMBAHASAN}

Multiple Intelligence dikenal dengan istilah kecerdasan majemuk. (Gardner, 2011) mengemukakan bahwa kecerdasan seseorang meliputi unsur-unsur yaitu 1) kecerdasan matematika logika (logical-mathematical intelligence);2) kecerdasan bahasa (linguistic intelligence);3) kecerdasan musikal (musical intelligence);4) kecerdasan visual spasial (spatial intelligence);5) kecerdasan kinestetik (kinesthetic intelligence);6) kecerdasan interpersonal (interpersonal intelligence);7) kecerdasan intrapersonal (intrapersonal intelligence); dan 8) kecerdasan naturalis (naturalis intelligence).

Menurut (Armstrong, 2009) tentang kecerdasan majemuk, Gardner berusaha memperluas ruang lingkup potensi manusia di luar batas/selain skor IQ. Menurut (Najafi et al., 2017) Teori kecerdasan ganda itu mengubah pandangan tradisional tentang kecerdasan dan mental kemampuan di bidang pendidikan dan ilmu kognitif dan secara signifikan mempengaruhi prosedur pendidikan dan Program latihan. Delapan kecerdasan Gardner telah diuraikan oleh (Booth \& O’Brien, 2008) dan diringkas sebagai berikut:

a) Kecerdasan verbal/linguistik melibatkan penguasaan bahasa melalui kombinasi mendengarkan, membaca, menulis dan berbicara; b) Kecerdasan matematika/logis terdiri dari 
kemampuan untuk mendeteksi pola, alasan secara deduktif, dan berpikir logis pada berbagai tingkat abstraksi; c) Kecerdasan visual/spasial melibatkan kemampuan untuk membuat dan memanipulasi citra mentaluntuk memecahkan masalah; d) Kecerdasan musik mengacu pada pemahaman nada, ritme, dan timbre untuk ditangkap perasaan atau mengekspresikan emosi; e) Kecerdasan tubuh/kinestetik terdiri dari kemampuan untuk memahami dunia melalui tubuh dengan memanipulasi objek atau menggunakan tindakan ringkas, terkontrol; f) Kecerdasan interpersonal mengacu pada kemampuan untuk menangkap dan membedakan suasana hati, perasaan dan motif orang lain untuk memfasilitasi komunikasi; g) Kecerdasan intrapersonal berkembang melalui sumber daya internal kami dan melibatkan kemampuan untuk mengetahui dan memahami pekerjaan batin seseorang sendiri; h) Kecerdasan naturalis/lingkungan melibatkan kemampuan untuk memahami simbol-simbol alam dan keseimbangan halus yang menopang kehidupan di planet kita.

Menurut (Plastoi, 2017) teori tentang kecerdasan ganda percaya manusia memiliki banyak kecerdasan,tetapi setiap orang memiliki profil unik ataukombinasi. Berdasarkan uraian tersebut dapat disimpulkan bahwa setiap manusia memiliki kecerdasan dan cendrung memiliki beberapa kecerdasan yang mendominasi. Kecerdasan-kecerdasan tersebut meliputi kecerdasan matematika logika (logical-mathematical intelligence), kecerdasan bahasa (linguistic intelligence), kecerdasan musikal (musical intelligence), kecerdasan visual spasial (spatial intelligence), kecerdasan kinestetik (kinesthetic intelligence), kecerdasan interpersonal (interpersonal intelligence), kecerdasan intrapersonal (intrapersonal intelligence), dan kecerdasan naturalis (naturalis intelligence). Berdasarkan uraian di atas dapat disimpulkan bahwa multiple intelligence adalah kecerdasan jamak yang mana masing-masing anak memiliki kecerdasan yang berbeda-beda. Kecerdasan tersebut mendominasi dari kecerdasan lainnya. Kecerdasan jamak itu meliputi: 1) kecerdasan matematika logika (logical-mathematical intelligence);2) kecerdasan bahasa (linguistic intelligence);3) kecerdasan musikal (musical intelligence);4) kecerdasan visual spasial (spatial intelligence);5) kecerdasan kinestetik (kinesthetic intelligence);6) kecerdasan interpersonal (interpersonal intelligence);7) kecerdasan intrapersonal (intrapersonal intelligence); dan 8) kecerdasan naturalis (naturalis intelligence). Adapun kecerdasan yang peneliti maksud adalah kecerdasan interpersonal.

Anak sebagai makhluk sosial membutuhkan orang lain dalam kehidupannya sehingga dibutuhkan kemampuan dalam berinteraksi dan menyesuaikan diri di lingkungannya yang biasa dikenal dengan istilah kecerdasan interpersonal. Hal tersebut harus dipersiapkan sejak dini yang dimulai dari persiapan dalam diri anak sendiri. Kecerdasan interpersonal di artikan sebagai kecerdasan dalam diri untuk mengenali dan memahami dirinya sendiri(Safitri et al., 2020). Kecerdasan interpersonal berkaitan dengan kehidupan sosial seperti berteman, bergaul atau bersosialisasi dengan orang lain, dan bekerja atau bermain secara berkelompok (Pratiwi et al., 2020)

Menurut (Putri et al., 2020) Kecerdasan interpersonal merupakan kemampuan mempersepsikan dan membedakan suasana hati, pikiran, keinginan serta kemampuan memberikan respon secara tepat terhadap orang lain. Dengan memiliki kecerdasan interpersonal, anak dapat merasakan apa yang dirasakan orang lain, menangkap maksud dari orang lain dengan bertindak sesuatu, serta mampu.dalam menjalin hubungan antar pribadi. Kecerdasan interpersonal merupakan kemampuan seseorang dalam memahami perasaan orang lain, memotivasi dan mudah memiliki hubungan sosial yang baik dengan lingkungan sekitar(Pahrul et al., 2019).Kecerdasan interpersonal adalah kemampuan anak berinteraksi dengan teman sebaya, anak belajar cara mengomunikasikan pikiran dan perasaannya secara efektif kepada orang lain, kemampuan untuk mengamati, mengerti maksud, motivasi dan apa yang dirasakan oleh seseorang(T. U. Putri et al., 2019).Kecerdasan interpersonal adalah kemampuan untuk membangun suatu hubungan yang meliputi kepekaan sosial dan komunikasi sosial yang ditandai dengan anak dapat mengemukakan pendapat kepada teman, kemampuan untuk mengerti dan menjadi peka terhadap perasaan, intense, motivasi, watak, temperamen orang lain, kepekaan akan ekspresi wajah, suara, isyarat dari orang lain. Anak sebagai makhluk sosial membutuhkan orang lain dalam kehidupannya sehingga 
dibutuhkan kemampuan dalam berinteraksi dan menyesuaikan diri di lingkungannya yang biasa dikenal dengan istilah kecerdasan interpersonal.

Berdasarkan uraian tersebut dapat disimpulkan bahwa Kecerdasan interpersonal merupakan kemampuan mengenali memahami dan memperkirakan perasaan, temperamen, suasana hati, maksud dan keinginan orang lain. Kecerdasan interpersonal merupakankemampuan anak berinteraksi dengan teman sebaya, anak belajar cara mengomunikasikan pikiran dan perasaannya secara efektif kepada orang lain, kemampuan untuk mengamati, mengerti maksud, motivasi dan apa yang dirasakan oleh orang lain di sekitarnya. Kecerdasan interpersonal adalah kemampuan untuk membangun suatu hubungan yang meliputi kepekaan sosial dan komunikasi sosial yang ditandai dengan anak dapat mengemukakan pendapat kepada teman, kemampuan untuk mengerti dan menjadi peka terhadap perasaan, intense, motivasi, watak, temperamen orang lain, kepekaan akan ekspresi wajah, suara, isyarat dari orang lain. Anak sebagai makhluk sosial membutuhkan orang lain dalam kehidupannya sehingga dibutuhkan kemampuan dalam berinteraksi dan menyesuaikan diri di lingkungannya yang biasa dikenal dengan istilah kecerdasan interpersonal. Hal tersebut harus dipersiapkan sejak dini yang dimulai dari persiapan dalam diri anak sendiri.

Kecerdasan interpersonal bermanfaat bagi anak dalam kehidupan bersosial. Salah satu kecerdasan yang penting distimulasi sejak usia dini adalah kecerdasan interpersonal karena dengan bertambahnya usia dini semakin memerlukan cara bersosialisasi dan berinteraksi dengan orang lain (Ariyanti, 2020). Anakyang memiliki kecerdasan interpersonal sangat membantu dalam anak penyesuaian idiri serta membentuk hubungan sosial yang lebih baik(Salsabilla \& Zafi, 2020).

Kecerdasan interpersonal merupakan hal yang sangat penting bagi kehidupan individu sebab dengan kecerdasan interpersonal yang tinggi individu tidak terlalu mengalami kesulitan dalam membina hubungan dengan orang lain, baik dengan orang yang baru dikenal maupun dengan teman lama(Samsaifil, 2020).Kecerdasaninterpersonal bagi anak usia dini memiliki manfaat yang besar bagi dirinya sendiri dan bagi perkembangan sosialnya karena anak perlu dibiasakan untuk bersosialisasi dengan lingkungannya, seperti pengendalian diri, komunikasi, simpati, empati, berbagi, serta dalam hal bekerjasama dengan orang lain(P. P. Putri et al., 2020).Kecerdasan interpersonal merupakan kecerdasan yang harus dikembangkan pada masa perkembangan anak sebagai proses pendewasaan agar anak mampu bersosialisasi dengan teman sebayanya, dapat mengendalikan emosinya sehingga anak dapat bekerja sama, bersimpati kepada teman temannya dan dapat terus berinteraksi dengan semua orang sampai kelak anak dewasa nanti(SN \& Zahro, 2020).Berdasarkan uraian tersebut dapat disimpulkan bahwa kecerdasan interpersonal bermanfaat dalam kehidupan social bermasyarakat anak. Kecerdasan interpersonal sangat membantu dalam anak penyesuaian idiri serta membentuk hubungan sosial yang lebih baik. Anak perlu dibiasakan untuk bersosialisasi dengan lingkungannya, seperti pengendalian diri, komunikasi, simpati, empati, berbagi, serta dalam hal bekerjasama dengan orang lain, dapat mengendalikan emosinya sehingga anak dapat bekerja sama, bersimpati kepada teman temannya dan dapat terus berinteraksi dengan semua orang sampai kelak anak dewasa nanti.

Anak yang memiliki kecerdasan interpersonal ccendrung cepat menyesuaikan diri dan disenangi teman-temannya. Anak yang memiliki kecerdasan interpersonal yang tinggi selalu merasa bosan dan tidak bergairah ketika bekerja sendiri serta sangat produktif dan berkembang saat belajar secara kooperatif dan kolaboratif (Wicaksono, 2020) .Karakteristik Kecerdasan interpersonal pada anak meliputi kemampuan anak dalam bersosialisasi dan berhubungan baik dengan teman, orang lain, dan lingkungan sekitarnya, bisa menyesuaikan diri, memahami dan menghargai pendapat serta perasaan orang lain (Carmanah \& Juherba, 2017). Karakteristik lainya seperti: saling sayang atau perhatian, sabar dan berbagi termasuk perilaku yang sering tampak pada anak-anak yang berhubungan dengan lingkungan sosial (Gunawan, 2020). Kecerdasan interpersonal anak dapat dilihat dalam kepekaan anak terhadap perasaan teman sebaya, kemampuan memotivasi dan mendorong orang lain, keramahan sikap dan kemampuan bersosialisasi, kecenderungan bekerjasama dengan orang lain dan berbagi, kemampuan menengahi 
konflik, dan hal-hal lain yang sifatnya berhubungan dengan orang lain(P. D. A. S. Putri et al., 2019).

Menurut (Umara et al., 2020) karakteristik individu yang menunjukkan kemampuan dalam intelegensi interpersonal antara lain: (1) Mampu bersosialisasi, menjadi mediator bermain dalam kelompok atau bekerja sama dengan tim; (2) Senang permainan berkelompok daripada individual; (3) Menjadi tempat mengadu orang lain; (4) Senang berkomunikasi verbal dan non verbal; (5) Peka terhadap teman; (6) Suka memberi feedback; (7) Mudah mengenal dan membedakan perasaan pribadi orang lain.Menurut(Agustina et al., 2020) kecerdasan interpersonal anak yang satu dengan yang lain tidaklah sama, masing-masing memiliki karakteristik yang berbeda-beda. Anak yang memiliki kecerdasan interpersonal biasanya mempunyai banyak teman, pandai bersosialisasi di manapun ia berada dan mampu menjaga hubungan sosial.Anak yang cerdas interpersonal kemungkinan berasal dari keluarga dengan pola asuh yang demokratis karena anak diberikan kesempatan untuk bertukar pendapat. Anak yang cerdas interpersonal kemungkinan pula berasal dari keluarga dengan pola asuh otoriter karena keluarga tidak berinteraksi baik dengan orang-orang di sekitarnya.

Kecerdasan Interpersonal mencakup kepekaan terhadap ekspresi wajah, suara, dan gerak tubuh dan kemampuan merespons isyarat-isyarat tersebut dalam beberapa pragmatis untuk mempengaruhi sekelompok orang agar mengikuti jalur tertentu dari suatu tindakan(Bahri \& Adiansha, 2020).Terdapat tiga dimensi kecerdasan interpersonal yaitu "sensivitas sosial (social sensitivy), pemahaman sosial (social insight), dan komunikasi sosial (social communication)"'(Pratiwi et al., 2020).

Menurut(Saraswati \& Putra, 2020) Indikator kecerdasan interpersonal “(1) sikap empati, (2) sikap prososial, (3) kesadaran diri, (4) pemahaman situasi sosial dan etika sosial pada anak, (5) pemecahan masalah efektif pada anak, (6) komunikasi efektif dan (7) mendengarkan efektif .Sedangkan menurut (Nurtika, 2019)Kecerdasan interpersonal mencakup kemampuan mempersepsi dan membedakan suasana hati, maksud, motivasi, serta perasaan orang lain. Kecerdasan ini meliputi kepekaan pada ekspresi wajah, suara, gerak isyarat, kemampuan membedakan berbagai macam tanda interpersonal dan kemampuan menanggapi secara efektif tanda tersebut.

Anak dengan kecerdasan interpersonal memiliki banyak kecakapan, yakni kemampuan berempati (berbagi, menolong dan membantu orang lain), kemampuan mengenali pikiran orang lain, kemampuan berteman, dan menjalin relasi social sehingga dapat membangun hubungan positif dengan orang lain(P. D. A. S. Putri et al., 2019). Kecerdasan interpersonal merupakan kemampuan dalam berpikir melalui komunikasi dengan orang lain yang meliputi kemampuan untuk bisa memimpin, mampu mengorganisasi, berinteraksi, berbagi, malakukan permainan kelompok, kerjasama, dansebagainya(Susiana, 2019). Berdasarkan uraian di atas dapat disimpulkan kompetensi kecerdasan interpersonal meliputi Kecerdasan Interpersonal mencakup kepekaan terhadap ekspresi wajah, suara, dan gerak tubuh dan kemampuan merespons isyaratisyarat tersebut.Selain itu kecerdasan interpersonal erat kaitannya dengan"sensivitas sosial (social sensitivy), pemahaman sosial (social insight), dan komunikasi sosial (social communication) yang meliputi“(1) sikap empati, (2) sikap prososial, (3) kesadaran diri, (4) pemahaman situasi sosial dan etika sosial pada anak, (5) pemecahan masalah efektif pada anak, (6) komunikasi efektif dan (7) mendengarkan efektif. Anak yang memiliki kecerdasan interpersonal mudah diterima di lingkungan masyarakat karena anak dengan kecerdasan interpersonal memiliki banyak kecakapan, yakni kemampuan berempati (berbagi, menolong dan membantu orang lain), kemampuan mengenali pikiran orang lain, kemampuan berteman, dan menjalin relasi social sehingga dapat membangun hubungan positif dengan orang lain. Dapat disimpulkan bahwa kecerdasan interpersonal meliputi kemampuan berinterksi atau komunikasi social dan etika sosial atau kesadaran diri.

Berdasarkan hasil observasi ditemukan bahwa faktor penghambat kecerdasan interpersonal anak meliputi lingkungan rumah anak yang individual sehingga anak terbiasa bersikap individual. Selain itu pola asuh orang tua yang terlalu otoriter sehingga anak cendrung berprilaku sesuai 
aturan tanpa di berikebebasan dalam beradaptasi atau berinteraksi di lingkungannya. Beberapa anak menyendiri dan takut dengan orang lain disebabkan karena terlalu dimanjakan oleh orang tua dan cendrung tidak membiarkan anak keluarrumah. Hal tersebut menjadikan anak takut dengan lingkungan sosial.

\section{SIMPULANDAN SARAN}

Kecerdasan interpersonal sangat penting bagi anak agar mudah diterima di lingkungan masyarakat karena anak dengan kecerdasan interpersonal memiliki banyak kecakapan, yakni kemampuan berempati (berbagi, menolong dan membantu orang lain), kemampuan mengenali pikiran orang lain, kemampuan berteman, dan menjalin relasi social sehingga dapat membangun hubungan positif dengan orang lain. Beberapafaktor penghambat kecerdasan interpersonal anak meliputi lingkungan rumah anak yang individual, pola asuh orang tua yang terlalu otoriter dan overprotectif. Oleh karenaitu guru maupun orang tua sebaiknya memperhatikan setiap perkembangan dank ecerdasan interpersonal anak sehingga anak mempunyai kemampuan interaksi yang baik dalam kehidupannya sehari-hari.

\section{DAFTAR PUSTAKA}

Agustina, R., Marlina, L., \& Fahmi, F. (2020). Hubungan Pola Asuh Orangtua dengan Kecerdasan Interpersonal Anak. THUFULI: Jurnal Pendidikan Islam Anak Usia Dini, 2(1), 31-44.

Ariyanti, E. (2020). Penggunaan Flashcard Emoji dalam Meningkatkan Kecerdasan Interpersonal Pada Anak TK A Sartiasari Surabaya. Jurnal Motorik:Media of Teaching Oriented and Children, 4(1), 120-129.

Armstrong, T. (2009). Multiple Intelligences in the Classroom. In Alexandria Virginia USA (3rd ed., Vol. 124, Issue 1). ASCD.

Bahri, S., \& Adiansha, A. A. (2020). Pengaruh Model Learning Cycle 7E dan Kecerdasan Interpersonal Terhadap Pemahaman Konsep IPA. Jurnal Pendidikan Anak, 6(1), 44-51.

Booth, R., \& O’Brien, P. J. (2008). An holistic approach for counsellors: Embracing multiple intelligences. International Journal for the Advancement of Counselling, 30(2), 79-92. https://doi.org/10.1007/s10447-008-9046-0

Carmanah, C., \& Juherba, E. (2017). Peningkatan Kecerdasan Interpersonal Anak Usia Dini melalui Permainan Tradisional Kucing dan Tikus. Jurnal Pelita PAUD, 2(1), 34-50.

Gardner, H. (2011). Frames of Mind The Theory of Multiple Intelligences.

Gunawan, D. (2020). Pengaruh Media Video Interaktif Terhadap Hasil Belajar Kognitif Kelasa IV SD Negeri 2 Karangrejo Trenggalek. Eduproxima: Jurnal Ilmiah Pendidikan IPA, 2(1), 1-9. https://doi.org/10.29100/eduproxima.v2i1.1489

Islami, N. (2016). Internalisasi Nilai-Nilai Karakter dalam Petuah Sumbang Duo Baleh Bagi Mahasiswi Asal Minangkabau di Kota Purwokerto Tahun 2016. International Conference of Moslem Society, 1(1), 44-59. https://doi.org/10.24090/icms.2016.1828

Kusumawati, I., \& Yasin, M. F. (2020). Implementasi Model Pembelajaran Tematik dan Kecerdasan Interpersonal Siswa SD terhadap Hasil Belajar Ilmu Pengetahuan Alam. Jurnal Akademika, 9(1), 47-68. https://doi.org/10.34005/akademika.v9i01.881

Najafi, M., Akouchekian, S., Ghaderi, A., Mahaki, B., \& Rezaei, M. (2017). Multiple Intelligences Profiles of Children with Attention Deficit and Hyperactivity Disorder in Comparison with Nonattention Deficit and Hyperactivity Disorder. Advanced Biomedical Research, 6(1), 1-7. https://doi.org/10.4103/abr.abr_222_15

Nurtika, E. (2019). Analisis Perkembangan Kecerdasan Interpersonal Anak dengan Metode Bermain Peran. (JAPRA) Jurnal Pendidikan Raudhatul Athfal (JAPRA), 2(1), 15-24. https://doi.org/10.15575/japra.v2i1.5309

Pahrul, Y., Hartati, S., \& Meilani, S. M. (2019). Jurnal Obsesi : Jurnal Pendidikan Anak Usia Dini Peningkatan Kecerdasan Interpersonal melalui Kegiatan Menggambar pada Anak Usia Dini. Jurnal Obsesi : Jurnal Pendidikan Anak Usia Dini, 3(2), 461-469. https://doi.org/10.31004/obsesi.v3i2.186 
Plastoi, C. D. (2017), the Theory of Multiple Intelligences and Their Impact on Learning Specific Movements in Swimming. Bulletin of the Transilvania University of Brasov, Series IX: Sciences of Human Kinetics, 10(1), 49-54. http://search.ebscohost.com/login.aspx?direct=true \&db=a9h\&AN=123847180\&site=ehostlive \&scope $=$ site

Pratiwi, I. G. A. R., Manuaba, I. B. S., \& Sujana, I. W. (2020). Kontribusi Kecerdasan Interpersonal dan Aktualisasi Diri dalam Kelompok Terhadap Kompetensi Pengetahuan IPS. Jurnal Ilmiah Sekolah Dasar, 4(2), 209-220.

Putri, P. D. A. S., Tirtayani, L. A., \& Suadnyana, I. N. (2019). Pengaruh Metode Proyek Berbasis Pendekatan Saintifik Terhadap Kecerdasan Interpersonal Anak Kelompok B Tk Gugus I Sukawati Tahun Ajaran 2018/2019. Jurnal Pendidikan Anak Usia Dini Undiksha, 7(1), 1324. https://doi.org/10.23887/paud.v7i1.18732

Putri, P. P., Sumardi, S., \& Mulyadi, S. (2020). Pengaruh Permainan Treasure Hunt terhadap Kecerdasan Interpersonal Anak Usia 5-6 Tahun. Jurnal PAUD Agapedia, 4(1), 118-130.

Putri, T. U., Israwati, \& Hijriati. (2019). Perkembangan Kecerdasan Interpersonal Anak melalui Metode Main Peran di PAUD Nurul Iman Banda Aceh. Jurnal Ilmiah Mahasiswa Pendidikan Guru Anak Usia Dini, 4(4), 11-15.

Safitri, B., Rustam, R., \& Rahmah, H. (2020). Upaya Meningkatkan Kecerdasan Interpersonal Anak melalui Metode Bermain Peran di RA Dharma Wanita Persatuan (DWP) Stain Datokarama Palu. Ana'Bulava: Jurnal Pendidikan Anak, 1(1), 1-16.

Salsabilla, S., \& Zafi, A. A. (2020). Kecerdasan Interpersonal Peserta Didik Sekolah Dasar. Terampil: Jurnal Pendidikan Dan Pembelajaran Dasar, 7(1), 35-42.

Samsaifil, S. (2020). Model Bimbingan Kelompok Berbasis Nilai Budaya Buton untuk Meningkatkan Kecerdasan Interpersonal Siswa. Gema Pendidikan, 27(1), 15-24.

Saraswati, P. I., \& Putra, M. (2020). Kontribusi Kecerdasan Interpersonal dan Sikap Ingin Tahu Terhadap Kompetensi Pengetahuan IPS. Mimbar PGSD Undiksha, 8(1), 89-99.

SN, N. Y., \& Zahro, I. F. (2020). Meningkatkan Kecerdasan Interpersonal pada Anak Usia 4-5 Tahun melalui Model Pembelajaran Reggio Emilia. Jurnal Ceria: Cerdas Energik Responsif Inovatif Adaptif, 3(3), 250-259.

Susiana, S. (2019). Pengaruh Kegiatan Bermain Drama terhadap Kecerdasan Interpersonal Anak Usia Dini di TK Mutiara Kenjeran Surabaya. Pedagogi: Jurnal Anak Usia Dini Dan Pendidikan Anak Usia Dini, 5(1), 109-116.

Umara, T. W. S., Damawanti, E. N., \& Arwansyah, Y. B. (2020). Dampak verbal bullying terhadap kecerdasan interpersonal siswa kelas II SD Muhammadiyah Gendol VI Seyegan Sleman Yogyakarta. Metalingua:Jurnal Pendidikan Bahasa Dan Sastra Indonesia, 5(1), 3540.

Wicaksono, A. (2020). Profil Pemecahan Masalah Matematika Siswa SMP dengan Kecerdasan Interpersonal ditinjau Berdasarkan Gender. Jurnal Pembelajaran Matematika Dan Sains, 1(1), 39-51. http://www.elsevier.com/locate/scp 